This item was submitted to Loughborough's Institutional Repository (https://dspace.lboro.ac.uk/) by the author and is made available under the following Creative Commons Licence conditions.

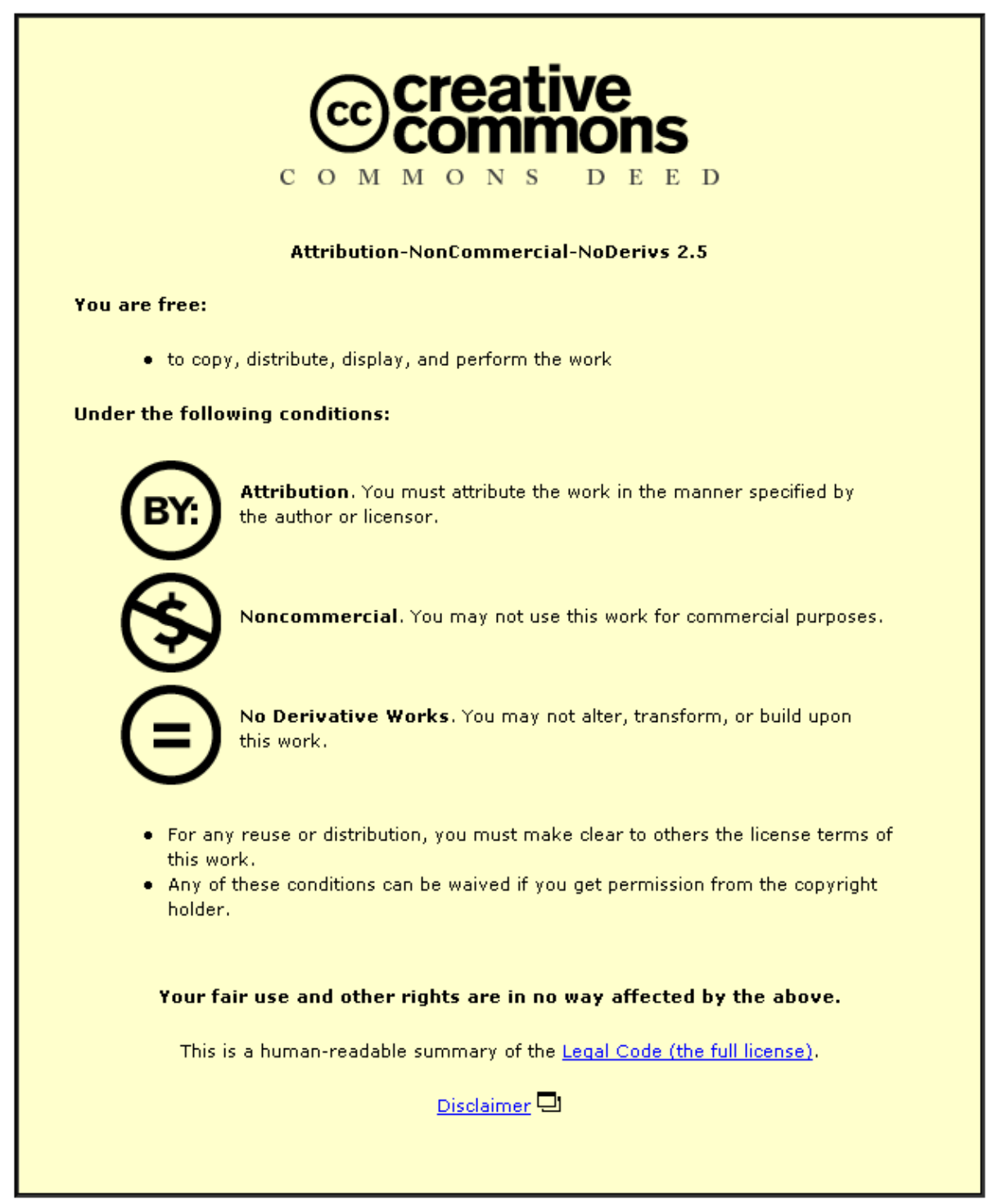

For the full text of this licence, please go to: http://creativecommons.org/licenses/by-nc-nd/2.5/ 


\title{
A Simple Model of PV System Performance and its Use in Fault Detection
}

\author{
S.K. Firth ${ }^{1}$, K.J. Lomas ${ }^{1}$ and S.J. Rees ${ }^{2}$ \\ ${ }^{1}$ Department of Civil and Building Engineering, Loughborough University, UK \\ ${ }^{2}$ The Institute of Energy and Sustainable Development, De Montfort University, Leicester, UK. \\ * Corresponding author. Tel: +44 (0) 1509228546. \\ E-mail address: S.K.Firth@1boro.ac.uk (S. Firth).
}

\begin{abstract}
Results are presented from a monitoring study of the performance of a sample of UK domestic PV systems. Five minutely average climatic and performance data was recorded for $27 \mathrm{PV}$ systems at two sites for up to two years of operation. On average, the annual energy losses due to faults were $3.6 \%$ (Site A, first year of operation), 6.6\% (Site A, second year of operation) and 18.9\% (Site B, first year of operation). Simple empirical models are constructed to describe the performance of the PV systems under 'normal operation' (when no faults occur). New analysis techniques are developed which estimate the energy losses of four different fault categories: sustained zero efficiency faults; brief zero efficiency faults; shading; and non-zero efficiency non-shading faults. The results demonstrate that faults have the potential to cause significant energy losses in domestic PV systems. The benefits of applying the data analysis techniques described in this work to PV system clusters and other urban micro-generation technologies are discussed.
\end{abstract}

\section{Keywords}

Photovoltaic; PV; monitoring; high resolution; analysis; model; fault detection; shading

\section{Introduction}

One of the main aims of research in building integrated PV systems is to improve the performance of installed PV systems. A drive for greater efficiency is necessary to increase the amount of electricity generated per Wp of installed PV capacity and so reduce the unit cost of the electricity. An essential part of such work is in understanding the energy losses which occur in installed PV systems and developing methods to minimise these energy losses. Some losses, such as the energy lost in the conversion of sunlight to electricity by the PV cell, are unavoidable and can only be significantly reduced by improvements in the technology of PV system components. Other energy losses, such as shading, are related to the installation of the PV systems and can be minimised through careful planning, design and operation. 
Energy losses in installed PV systems can be detected by monitoring the operational performance and analysing the recorded data. Monitoring of PV systems has been used to develop guides and benchmarks for PV system performance (IEA, 2000). Demonstration PV systems (usually among the first PV systems to be installed in a country) and systems with unique characteristics (such as new cell technologies or novel construction techniques) often have their performance monitored in detail. Such monitoring studies record the performance of the PV systems, analyse the energy losses and provide recommendations to improve the design of future systems (e.g. Roaf and Fuentes, 1999). This becomes an iterative process when the next generation of PV systems incorporating the design improvements are themselves monitored and used to develop further recommendations to raise efficiency (Erge et al., 2001).

PV systems are often monitored according to standards, for example the British Standard BS EN 61724 (BSI, 1998) and the recorded data analysed on an annual basis (e.g. IEA, 2004). Annual results illustrate the performance of the system over a significant time period of operation, account for the effect of seasonal variation and can be used for comparison with benchmark values. This shows when systems are performing poorly (such as low electricity generation when compared to similar systems) however it cannot be use to explain why this poor performance occurs. Monitoring and analysis must be carried out at much higher resolution (for example daily, hourly or minutely) to fully investigate the many factors which affect PV system performance.

High resolution monitoring studies make use of data with a short recording interval, for example minutely to hourly intervals, and a relatively small number of measured parameters, such as solar irradiance and electricity generation (Drews et al., 2007; Oozeki et al., 2003; Pearsall and Hynes, 2003; Reinders et al., 1999; Baltus et al., 1998). Energy losses in the PV systems are assessed by investigating the trends and patterns in the recorded data. Sometimes simulation tools are used to estimate energy losses where they are difficult to identify directly. These studies often analyse the recorded data in sections, for example day-by-day or month-by-month sections, to investigate particular energy losses such as shading. Few of the studies make use of high-resolution data recorded below hourly intervals.

The aim of this work is to investigate PV system performance and operational faults, based on a highresolution monitoring study of a sample of UK domestic PV systems. Performance and climate data was collected at five minutely intervals for one or two year periods for twenty six grid-connected domestic PV 
systems. Using the monitored data, a novel empirical model of PV system performance is developed which is based on the relationship between five minutely in-plane solar irradiance and five minutely system efficiency. The model is used to identify faults that occur during operation and these are divided into four categories: sustained zero efficiency; brief zero efficiency; shading; and non-zero efficiency, non-shading. For each fault category the energy losses are calculated and the results are used to draw conclusions regarding the potential effect of faults on the overall performance of domestic PV systems.

\section{Data measurement and collection}

Twenty seven grid-connected domestic PV systems had their performance monitored in this study (Table 1). The systems were installed as part of the UK Government's Photovoltaic Domestic Field Trial (BRE, 2006) and were placed on social housing at two sites (Figure 1). Site A consisted of twenty two roofintegrated PV systems with ratings from $1.53 \mathrm{kWp}$ to $1.7 \mathrm{kWp}$ installed on new-build terrace single storey dwellings in 2002. Site B had five roof-mounted PV systems from $1.44 \mathrm{kWp}$ to $1.68 \mathrm{kWp}$ retrofitted onto existing two-storey terrace blocks in 2003. All the systems were single string and had a single inverter. The systems were grid-connected and supplied electricity to the dwellings as well as exporting excess to the mains electricity grid. The PV systems were monitored at five minutely intervals for a period of two years at Site A and one year at Site B. Monitoring systems were set up at each site to record the performance of the PV systems and the electricity flow between the dwellings and the mains electricity grid (Figure 2). Horizontal solar irradiance and ambient air temperature were recorded at one location for each site. In-plane solar irradiance and PV module temperature were recorded for each group of PV arrays with different orientation and tilt: one such measurement at Site A and two at Site B. Solar irradiation was measured using PV cell sensors located close to the PV arrays and in an unshaded location. The DC electrical energy input to the inverter, AC electrical energy output from the inverter, import of electricity (from the mains grid) and export of electricity (to the mains grid) were recorded for each dwelling. Only electrical energy was measured at the inverter and separate current and voltage measurements were not taken. All the measured parameters were sampled at ten second to one minute intervals and were recorded at five minutely time intervals.

The measured data was collected by on-site data loggers. These were connected to the public telephone network using modems and the collected data was regularly downloaded. Due to the amount of data collected, a series of algorithms were developed in specialised data analysis software IDL (RSI, 2005) to convert the 
raw data files into a standard format. This involved placing the five minutely values of each parameter (such as horizontal solar irradiance) into separate files. Each parameter was then checked for missing data and error values. The plausibility of the data was also evaluated by checking that the magnitude and variation (diurnal or seasonal) of the data was as expected. For example, the ambient air temperature measurements were compared with those of nearby weather stations. Further IDL routines were then developed to analyse the five minutely data in detail.

\section{$3 \quad$ PV system fault categories}

Many types of energy losses occur in PV systems during the process of converting of solar radiation to electricity. This work classifies PV system performance as occurring in three states: ideal, normal and actual. Ideal operation represents the PV system operating at ideal conditions, with system efficiency equal to the PV module rated efficiency and no other losses. This is a theoretical mode of operation that could not be achieved in practice. Normal operation describes the expected operation of a well-designed and performing PV system. The system efficiency at normal operation is lower than the ideal because of operational losses: inherent, unavoidable losses that occur in all installed PV systems such as temperature losses and inverter conversion losses. Actual operation represents the monitored performance of the PV system. System efficiency at actual operation may be lower than at normal operation due to faults, additional energy losses in the system which are considered avoidable and not a part of normal operation.

Based on previous monitoring studies, discussions with PV installers and the technical documentation of the PV system components, six types of faults were identified: component failure; system isolation; inverter shutdown; shading; inverter maximum power point (MPP) tracking failure; and other faults (Table 2). System isolation was further classified as either sustained system isolation (lasting for a day or longer) or brief system isolation (lasting less than a day). Shading was included as a fault as it is avoidable and not considered a part of normal operation as defined in this work. It was not possible to identify all of the seven fault types individually from the monitored data and so the faults were placed into four fault categories: sustained zero efficiency; brief zero efficiency; shading; and non-zero efficiency, non-shading. These fault categories were identified in the monitored data using the diagnostic methods described in Table 2. 


\section{The performance model}

A model was constructed to describe the performance of a well operating PV system at the five minutely level. Performance was assessed using the system efficiency, which is defined as the ratio of the AC energy output from the inverter to the in-plane solar energy on the PV array:

$\eta_{S}=\frac{E_{A C}}{G_{i} \times A}$

where $\eta_{\mathrm{S}}$ is the five minutely PV system efficiency; $E_{A C}$ is the electrical energy output from the inverter recorded over a five minute period $(\mathrm{Wh}) ; \mathrm{G}_{\mathrm{i}}$ is the in-plane solar irradiation received on an unshaded surface of the same location, orientation and tilt as the PV array over a five minute period $\left(\mathrm{Wh} / \mathrm{m}^{2}\right)$; and $\mathrm{A}$ is the area of the PV array $\left(\mathrm{m}^{2}\right)$

Taking one of the monitored PV systems as an example, a plot of the five minutely in-plane solar irradiance against five minutely system efficiency for a one year monitoring period produces a boomerangshaped cloud of points (Figure 3). For ease of comprehension, the average in-plane solar irradiance $\left(\mathrm{W} / \mathrm{m}^{2}\right)$ is shown on the $\mathrm{x}$-axis of the figure rather than the five-minutely total solar irradiation $\left(\mathrm{Wh} / \mathrm{m}^{2}\right)$. Similar relationships of solar irradiance and system efficiency were observed for the other monitored PV systems in this study. The system efficiency rises from zero at zero solar irradiance to values in the range 0.08 to 0.10 for irradiances above $300 \mathrm{~W} / \mathrm{m}^{2}$. This cloud of points approximates the solar irradiance to efficiency relationships for PV modules seen under laboratory conditions (Bücher and Kunzelmann, 1998) and comparable results have been reported for installed PV systems (Oozeki et al., 2003; Kiefer et al., 1995). The low efficiency values observed at low solar irradiances corresponds with the findings of pervious work which describes the significant reduction in PV module efficiency at low light levels (Bücher, 1997). A cloud of points rather than a straight line occurs because even in normal operation the temperature of the array will change and the inverter will not precisely track the point of maximum power output, thus the overall efficiency varies. For the array shown in Figure 3 the maximum system efficiency values decrease at higher irradiances, from around 0.10 at $300 \mathrm{~W} / \mathrm{m}^{2}$ to 0.08 at $1200 \mathrm{~W} / \mathrm{m}^{2}$. This is because higher solar irradiances heat the array which leads to increased temperatures and a systematic reduction in energy generation. In two systems at Site B it was noticeable that inverter derating was taking place, when the power output from the PV array was greater than the maximum power input of the inverter and so there was a loss in output power 
from the systems. Inverter derating occurs in PV systems when the rating of the inverter is undersized compared to the rating of the PV array. However, for the two systems at Site B the inverter derating only occurred at solar irradiance greater than around $1000 \mathrm{~W} / \mathrm{m}^{2}$ and so the effects on energy generation were minimal.

In Figure 3 there are also some instances of system efficiency values below the cloud of points. The assertion in this work is that the system efficiencies which lie within the dense boomerang-shaped cloud describe the normal operation of a PV system. The data points that lie below the boomerang-shaped cloud are assumed to be caused by faults. To identify the faults it was necessary to define the boundaries of the cloud within which operation was deemed to be normal. A numerical approach to do this was adopted in which the efficiency values were placed in narrow solar irradiance bins. One difficulty when choosing irradiance bins was that the majority of irradiance values occurred at low levels of irradiance. Using bins of constant size (for example $50 \mathrm{~W} / \mathrm{m}^{2}$ ) meant that the low irradiance bins (i.e. $100 \mathrm{~W} / \mathrm{m}^{2}$ to $150 \mathrm{~W} / \mathrm{m}^{2}$ ) contained many more values than the high irradiance bins (i.e. $900 \mathrm{~W} / \mathrm{m}^{2}$ to $950 \mathrm{~W} / \mathrm{m}^{2}$ ). Small bin sizes were required at low irradiance to account for the rapid change in system efficiency at irradiances less than $300 \mathrm{~W} / \mathrm{m}^{2}$. However small bin sizes at the higher irradiances meant that some bins would not contain any efficiency values at all. The problem was overcome by using irradiance bins of variable size so than they contained a constant number of values. Irradiance bins were generated which contained 300 system efficiency values in each irradiance bin. The first 300 irradiance values above $50 \mathrm{~W} / \mathrm{m}^{2}$ were placed in the first bin, the next 300 irradiance values were placed in the second bin, and the process was repeated for the whole range of irradiance values. A lower threshold of $50 \mathrm{~W} / \mathrm{m}^{2}$ was used to exclude from the analysis the high numbers of very low irradiances where energy generation was minimal.

Using this technique the irradiance values recorded over one year for one system were separated into 114 variable width irradiance bins. The smallest size was $1.44 \mathrm{~W} / \mathrm{m}^{2}$ (from $50.04 \mathrm{~W} / \mathrm{m}^{2}$ to $51.48 \mathrm{~W} / \mathrm{m}^{2}$ ) and the largest was $106.44 \mathrm{~W} / \mathrm{m}^{2}$ (from $1033.32 \mathrm{~W} / \mathrm{m}^{2}$ to $1139.76 \mathrm{~W} / \mathrm{m}^{2}$ ). Within each bin the majority of efficiency values were clustered around a central value with a modal frequency at or near the central value. The frequency of occurrence of values decreased above or below the central value (Figure 4). The efficiencies around the central value represent the system working well with significantly lower values representing faulty performance. 
The distribution of values in each bin was represented by a normal distribution and a least-squares curve fitting procedure was used to determine the mean and standard deviation of the distribution. For the example shown in Figure 4, the procedure gave a mean $\eta_{\mathrm{S}}$ of 0.87 and a standard deviation of 0.0065 . To define the upper and, more importantly, the lower boundaries of the boomerang-shaped cloud a $95 \%$ confidence interval was used. It was assumed that when the probability of occurrence of a $\eta_{\mathrm{S}}$ value was less than $2.5 \%$ (i.e. 1.96 standard deviations below the mean) it represented faulty performance. For the example bin, therefore, all $\eta_{S}$ values lower than 0.072 were taken as being due to system faults; there were 11 such faults in the example (Figure 4).

By combing the results from all bins the boundary of the boomerang-shaped cloud within which operation was deemed to be normal could be defined. For the example system, for which 114 irradiance bins were used, this numerical model indicated that $6 \%$ of the values recorded during daylight hours (when the sun was above the horizon) represented faulty operation (Figure 5). These faults were then further studied, using the diagnostic methods outlined in Table 2, to determine the likely cause. This numerical method of data analysis, which is only briefly described here, is explored in greater detail along with many more example applications in Firth, 2006.

\section{Categorising the faults}

\subsection{Sustained and brief zero efficiency faults}

Zero efficiency faults were defined as occurrences of zero efficiency during daylight hours. To account for the effects of the recording interval, any fault immediately before or after such a fault (or a sequence of such faults) was also identified as a zero efficiency fault. The durations of the zero efficiency faults were calculated and sustained zero efficiency faults defined as those with durations of a day or longer. Such events were attributed to component failure or sustained system isolation. Brief zero efficiency faults, of duration one day or less, were attributed to inverter shutdown or brief system isolation (for example maintenance work).

\subsection{Shading faults}

Shading occurs when an external object lies between the sun and the PV array. As the arrays were stationary, and assuming the shading object did not move with time, the position of the sun is the factor which determines the shading effect. In previous studies (for example Uchida et al., 2001) the shading effect was 
taken to be a function of the time of day and time of year. However the use of sun position removes the need to consider these additional variables and offers much greater insight into the problem.

The position of the sun was calculated for each five minutely interval using the time and date and the latitude of the PV site. Sun position was defined by the solar azimuth $\alpha$ (the angle between the bearing of the sun and due south, where east is taken to be positive and west negative) and solar elevation $\beta$ (the angle made between the sun and the horizon). The size of shading objects that occur in the built environment mean that, if a fault is caused by shading, it is likely that there would be additional faults at nearby sun positions. Thus shading can be identified by the occurrence of a high number of faults within a small region of specific sun positions. The shading faults will have non-zero efficiency as, although the sun itself is entirely or partially obscured (behind a solid object or partly behind it, or obstructed by a non-solid object such as a tree), the daylight from the sky (as diffuse radiation) will still fall on the array. To apply this analysis the zero efficiency faults were ignored.

Relatively high concentrations of faults occur at the beginning and end of each day (at times of low solar elevations) due to unavoidable shading (such as the sun rising behind the array or being obscured by other objects within the immediate urban area). These unavoidable faults were also excluded by ignoring faults that occurred at solar incidence angles of greater than $80^{\circ}$. Thus the shading faults identified are those which may, in principle, be avoided by more careful positioning of the PV array and not those which are always unavoidable with static arrays in urban setting. Passing clouds which shade the PV arrays but not the solar irradiance sensors, or vice versa, might also result in faults that could be incorrectly identified as shading. However this is effect is considered to be minimal due to the proximity of the PV arrays and the irradiance sensors and the length of the 5 minutely recording interval.

The non-zero faults were plotted on solar azimuth versus solar elevation axes. As an example, for one system at Site A, a high concentration of faults was observed in the middle of the day during autumn, winter and spring $\left(-40^{\circ}<\alpha<40^{\circ}\right.$ and $\left.\beta<40^{\circ}\right)$ and a low concentration in summer (Figure 6). A rules-based system was developed to identify which of the faults were caused by shading. It was assumed that shading would occur at similar sun positions and so a concentration of non-zero efficiency faults in a particular region of sun position would indicate a shading effect. About each individual fault a region of sun positions was defined as:

$$
\alpha_{0}-\Delta \alpha / 2<\alpha<\alpha_{0}+\Delta \alpha / 2
$$




$$
\beta_{0}-\Delta \beta / 2<\beta<\beta_{0}+\Delta \beta / 2
$$

where $\alpha_{0}$ and $\beta_{0}$ were the solar azimuth and solar elevation of the fault and $\Delta \alpha$ and $\Delta \beta$ describe the width and height of the sun position region.

From inspection and several trials, the size of the sun position region was fixed at $\Delta \alpha=10^{\circ}$ and $\Delta \beta=5^{\circ}$. The number of faults within this region was calculated and expressed as a percentage of the total number of five minute sun positions that occurred within the region. A fault concentration parameter FC was defined to describe the concentration of faults and calculated using the following equation:

$$
F C_{\alpha_{0} \beta_{0}}=\sum_{\alpha_{0}-\Delta \alpha}^{\alpha_{0}+\Delta \alpha} \sum_{\beta_{0}-\Delta \beta}^{\beta_{0}+\Delta \beta} F / \sum_{\alpha_{0}-\Delta \alpha}^{\alpha_{0}+\Delta \alpha} \sum_{\beta_{0}-\Delta \beta}^{\beta_{0}+\Delta \beta} S
$$

where $F C_{\alpha_{0} \beta_{0}}$ is the fault concentration about sun position $\alpha_{0} \beta_{0}, \mathrm{~F}$ is the number of faults within the sun position region and $\mathrm{S}$ is the number of five minute sun positions within the sun position region.

As an example, for the example PV system in Figure 6 a fault occurred at sun position $\alpha=11.5^{\circ}$ and $\beta=$ $40.5^{\circ}$. The sun position region is $6.5^{\circ}<\alpha<16.5^{\circ}$ and $38.0^{\circ}<\beta<43.0^{\circ}$ and within this region 16 faults occurred during the first year of operation (Figure 7). The total number of five minutely occurrences of sun position within the region was 160 and the fault concentration for this single fault was therefore calculated as 0.1 (or $10 \%)$.

If the fault concentration value exceeded a threshold value then shading was deemed to have occurred. Through visual inspection of the monitored datasets in this study and by comparison with a shading model based on the site geography for a sample of the PV systems, a threshold of $12 \%$ was set (for further detail of this process see Firth, 2006). Thus shading was identified as faults with a fault concentration value of greater than $12 \%$.

For the example PV system the number of faults deemed to be caused by shading were 3224 of the 3888 total of non-zero faults (Figure 6). At this site there was a large tree to the south of the array and the high concentration of faults around zero solar azimuth illustrates the shading effect of the tree. There was also a raised roof to the west of the array (Figure 6). Further visual verification of the shading method was obtained through analysis of the PV systems located on adjacent roofs to the example system above. In the adjacent 
systems the shading effects of the tree were shifted to the south east (for the system to the west) and the south west (for the system to the east).

\subsection{Non-zero efficiency non-shading faults}

The remaining faults, not identified as either zero efficiency or shading faults, tended to be brief and there was no discernable pattern to their occurrence. This is demonstrated by plotting the occurrences of these faults for an example PV system at Site B on date and time of day axes (Figure 8). The times of sunrise and sunset are also shown on the figure. The non-zero efficiency non-shading faults were significant for this PV system and occurred for over $12.9 \%$ of daylight hours. The average duration of the faults was 11 minutes and the faults occurred at both low and high solar irradiances. This type of fault could be caused by several possible factors; inverter maximum power point tracking failure is thought to be one likely cause.

To illustrate the different effects of the fault types, the faults that occurred during operation for the example PV system given in Figure 3 and Figure 5 were plotted according to the four fault categories (Figure 9). For this PV system there were no periods of sustained zero efficiency faults. The brief zero efficiency faults and non-zero efficiency non-shading faults were present over the full range of solar irradiance from 50 $\mathrm{W} / \mathrm{m}^{2}$ to $1250 \mathrm{~W} / \mathrm{m}^{2}$. Shading faults occurred at solar irradiance below around $500 \mathrm{~W} / \mathrm{m}^{2}$ (as the system was shaded at the end of the day when solar irradiances were low). The shading and non-zero efficiency nonshading faults had system efficiencies which ranged from slightly below normal operation to near zero values.

\section{Calculating energy losses due to faults}

The energy losses due to a fault were calculated by comparing the system efficiency recorded as the time of the fault to the system efficiency of normal operation. Normal operation system efficiency was taken as the mean of the fitted Normal distribution curve for the irradiance bin in which the fault occurred. As an example, in one PV system a single five minutely fault occurred at an irradiance of $600 \mathrm{~W} / \mathrm{m}^{2}$ with an efficiency of 0.040. If the fault had not occurred, and the system had been at normal operation, then the efficiency can be estimated to be 0.087 (given by the fitted Gaussian curve). The fault therefore caused a 0.047 reduction in efficiency. For each fault the loss in energy was calculated using the following equation:

$$
e_{F}=\left(\eta_{N O, i}-\eta_{S}\right) \times G_{i} A
$$


where $e_{F}$ is the energy loss due to an individual fault (Wh); $\eta_{N O, i}$ is the system efficiency of normal operation at irradiance $i$; $\eta_{S}$ is the system efficiency of the fault; $G_{i}$ is the in-plane solar irradiation energy $\left(\mathrm{Wh} / \mathrm{m}^{2}\right)$; and $A$ is the area of the PV array $\left(\mathrm{m}^{2}\right)$

\section{Annual performance results of the PV systems}

\subsection{Annual occurrences of faults}

The techniques in the previous section identified a significant number of faults in the monitored PV systems. To investigate the extent of the faults, the number of faults that occurred during operational hours was calculated. Operational hours were defined as daylight hours when the in-plane irradiance was greater than $50 \mathrm{~W} / \mathrm{m}^{2}$, which is the time when the PV systems should have been operating. For each PV system the total number of faults that occurred during operation was expressed as a percentage of operational hours. Summary statistics of these values were calculated (Table 3). The systems at Site A suffered faults for an average of $7.1 \%$ of operational hours in the first year of operation and $8.2 \%$ in the second year of operation. At Site B, faults occurred for an average of $19.9 \%$ of the time in the first year of operation. On average, in the first year at Site A, high numbers of shading faults (3.0\%) and non-zero efficiency non-shading faults $(2.9 \%)$ were observed. In the second year sustained zero efficiency faults had the highest number of occurrences (an average of $3.4 \%$ ) due to the failure of one of the PV systems over a long time period. The percentage hours for which shading resulted in losses was the same in both years, which is to be expected. In contrast, the occurrence of other faults, which are due to non-systematic events, varied from year to year. At Site B the number of faults due to sustained zero efficiency was the greatest $(11.7 \%)$ followed by non-zero efficiency non-shading faults $(6.2 \%)$. At Site B the number of shading faults was low $(0.6 \%)$.

\subsection{Annual energy losses due to faults}

For each PV system the annual final yield was calculated together with the losses in final yield due to faults (Table 4). Final yield is defined as the actual energy generation of the system normalised by the system's rated power (which allows comparison between systems of different sizes). The annual final yield at normal operation, calculated by summing the actual final yield and the final yield losses due to faults, is also shown in the table. The percentage energy losses due to faults (given as a percentage of the normal operation final yields) were also calculated (Table 5). The expected annual final yield for a well operating PV system is typically around 700 to $800 \mathrm{kWh} / \mathrm{kWp}$ for the UK climate (BRE, 2006). The PV systems at Site A operated 
on average within this range $(775 \mathrm{kWh} / \mathrm{kWp}$ in the first year and $745 \mathrm{kWh} / \mathrm{kWp}$ in the second year). The decrease in average performance from the first to second year at Site A was largely due to one PV system which failed for several months in the second year and suffered a loss of $395 \mathrm{kWh} / \mathrm{kWp}$. At Site B the PV systems appeared to be operating poorly with low average annual final yield ( $469 \mathrm{kWh} / \mathrm{kWp})$.

On average, the total energy losses due to faults were $3.6 \%$ at Site A during the first year, $6.6 \%$ at Site A during the second year and $18.9 \%$ at Site B. Sustained zero efficiency faults caused the largest energy losses with an average of $4.3 \%$ at Site $\mathrm{A}$ in the second year and $11.6 \%$ at Site B. In both cases these high average figures were strongly influenced by individual systems which had failed and were not repaired for several months. The second largest energy loss at Site A was shading (an average of $1.6 \%$ in the second year) followed by non-zero efficiency non-shading faults and then brief zero efficiency faults. At Site B however shading only had a minimal effect and the second largest loss was non-zero efficiency non-shading faults (an average of $4.8 \%$ ). Brief zero efficiency faults also had a significant effect at Site B with an average energy loss of $2.2 \%$.

To illustrate the effects of faults on individual systems, the percentage energy losses due to faults is plotted for eight selected PV systems (where the total energy loss due to faults was $5 \%$ or greater) during the first year of operation (Figure 10). Systems B-3 and A-5 had the largest energy losses (59\% and 29\%) primarily caused by sustained zero efficiency faults. System B-2 had the third largest energy losses (23\%) however this was caused by a combination of non-zero efficiency non-shading faults and brief zero efficiency faults. The remaining systems all have energy losses below $10 \%$ caused by a mixture of the four fault types. Shading, although present in many systems for periods of up to several months, did not cause large energy losses in individual systems and the maximum individual shading loss was $4.9 \%$ at System A-3. Overall, the sustained zero efficiency loss at System B-3 (58\%) was greater than the combined fault energy losses of all other systems at Site B. Further investigation is required to explain the large number of brief faults which occur at Systems B-1 and B-2. The brief faults appear to be random in nature and there is no clear explanation for their occurrence. One possibility is that, for some PV systems, high mains network voltages may cause the inverter to repeatedly shut down for brief periods. Additional measurements of network voltages are required to confirm this explanation. 


\subsection{Monthly shading results}

The technique for identifying shading in the PV systems can be tested further by investigating the energy losses on a monthly basis. For the PV system with the largest shading loss (System A-3) the monthly energy loss due to shading and the monthly normal operation final yield were calculated for the two year monitoring period (Figure 11). The normal operation final yield (which excluded the effects of the shading) varied as expected across the seasons (high in summer and low in winter). The shading energy losses occurred approximately from September to April each year with a maximum loss of $25 \mathrm{kWh} / \mathrm{kWp}$ in October 2003. Overall energy loss due to shading was $6.1 \%$ of the normal operation final yield for the two year period. This shading was caused by a large tree to the south of the PV array (as discussed in Section 5.2) and in summer there was no shading as the solar elevation was high and the direct sunlight was not blocked by the tree. The tree was deciduous and this can be seen in the monthly energy losses. In autumn the monthly shading energy loss was greatest as the tree was still in leaf. In spring the shading losses are lower, as the leaves on the tree are either not present or just beginning to grow. This observation provides confidence in the techniques used to identify shading in the monitored performance data.

\section{Applications of the fault detection techniques}

New data analysis techniques have been described which identify the occurrence of faults during the operation of PV systems. For the 27 PV system monitored in this study, energy losses due to faults at Site A averaged $3.3 \%$ in the first year of operation and $6.6 \%$ in the second year of operation (calculated as a percentage of the energy generation assuming that no faults had occurred). At Site B the average energy loss due to faults was $18.9 \%$ during the first year of operation. This represents a significant reduction of the energy generated from the PV systems and potentially a loss in income from the sale of excess electricity. These figures are based on a small sample of PV systems and should not be taken to be representative of the performance of PV systems generally. The advantage of the analysis techniques presented in this work, rather than more simple analyses based on hourly or monthly data, is that the reasons for the energy losses due to faults can be explained in detail and the reduction in electricity generation quantified.

The analysis techniques utilise only two measurement parameters, in-plane solar irradiance and AC energy output from the inverter, which are measured at high-resolution (five-minutely intervals in this study). This means that only two measurement sensors are needed. For clusters of PV systems, the solar irradiance has 
only to be measured for a single location at the site (provided the arrays all face the same direction and have the same tilt) which further simplifies the monitoring system requirements. It would be possible to utilise the same analysis techniques with data recorded at other time intervals. Higher resolution data (such as minutely data) would improve the diagnostic power of the techniques, in particular for the brief zero efficiency and non-zero efficiency non-shading faults. At lower resolution (such as hourly or half-hourly data) the techniques would still detect and explain the occurrence of faults but with a reduced degree of accuracy. For example, when using hourly data, some faults may cause small reductions in system efficiency which might remain undetected as noise in the 'cloud of points' representing normal operation. A key requirement of the fault diagnostic techniques is that the solar radiation measurements are accurate, in particular that the solar radiation sensor is not shaded at any time of the day or year. Inaccurate solar radiation measurements have a significant impact on the formation of the normal operation 'cloud of points' and make the construction of the empirical models impractical.

The minimal monitoring system requirements means that the data analysis techniques could be applied to individual systems installed on domestic buildings in a street, to a housing estate or to other localised clusters. Alternatively large PV systems on non-domestic buildings could be assessed, in particular systems which comprise of a series of inverters each with their own array. The monitoring system would consist of meters fitted to each inverter to record the AC energy output and radiation sensors to record the local solar irradiation. High resolution data would be collected using individual data loggers and uploaded daily to a central server using radio or GSM communication. As the data collection progressed the normal operation 'boomerang cloud of points' would be built up for each PV system. Using the fault detection techniques it would then be possible to identify faults as they occur. For faults which can be corrected by maintenance work (in particular sustained zero efficiency faults caused by component failure or system isolation) this monitoring approach would provide an alarm system to notify the PV system operators to carry out remedial work. This strategy would have minimised the high energy losses observed in the monitored PV systems caused by sustained zero efficiency faults, which resulted in an annual energy loss of $58 \%$ in one case.

Implementation of the monitoring strategy for PV system clusters would also allow the energy losses due to shading to be calculated. Shading faults are dependent on the shape, size and proximity of the surrounding urban environment which blocks direct solar radiation and, unlike component failures or system isolation, 
cannot be corrected by maintenance work to the PV systems themselves. This presents a unique difficulty for PV system management in urban settings as the decisions of third parties within the locality can impact on the electricity generation, and thus the financial viability, of a PV system. For clusters of PV systems, the results of the shading analysis could be used in discussions of solar access rights with third parties, including planned extensions to nearby buildings, the maintenance regime of public trees and hedges, and the placement or removal of local street furniture (such as signs and streetlights). At one of the monitored PV systems it was seen that the shading from a single tree caused an annual energy loss of $6.9 \%$ and this information would be essential if a case had to be made to a third party to have the tree removed or pruned to minimise the shading effect.

Finally, the monitoring strategy would enable the detection of brief low or zero efficiency faults in PV system clusters which largely go unnoticed in current PV system monitoring schemes. These brief faults have the potential to cause significant energy losses in PV systems; in the case of one of the systems monitored in this work an annual energy losses of $23 \%$ was observed. The reasons for these faults can vary and so might the solution. For example, if high mains grid voltages were causing the inverters to repeatedly shut down then this would need to be raised with the operator of the local distribution network. Alternatively if there were significant occurrences of inverter maximum power point tracking failure (when the inverter failed to track the optimum voltage for power generation) then this would need to be referred to the inverter manufacturers. In either case, the detection and calculation of the effects of these brief faults would be essential.

The basic concept of the monitoring approach is the study of high resolution data measured for a small number of parameters and it may be possible to extend this approach for other micro-generation systems. For example the techniques could be used to better understand of the performance of wind turbines installed in urban settings and evaluate the effects of faults such as wind shadow. Further work is needed to investigate such possibilities.

\section{Conclusions}

A study of domestic PV systems in the UK has been carried out and the faults that occur during operation classified. High resolution (five minutely) performance data, recorded for $27 \mathrm{PV}$ systems at two sites over a one or two year period, has been used to construct simple empirical models of the performance of the PV systems during normal operation (defined as operation when no faults occur). Novel analysis techniques have 
been developed which identify the faults that occur during operation and quantify the energy losses due to these faults. The techniques distinguish four categories of faults: sustained zero efficiency faults; brief zero efficiency faults; shading faults; and non-zero efficiency non-shading faults.

The following conclusions were drawn from the study:

- The overall annual energy losses due to faults (calculated as a percentage of the energy generation assuming no faults occurred) varied from an average of $3.6 \%$ at Site A to an average of $18.9 \%$ at Site B. This clearly shows that faults have the potential to cause significant losses in electricity generation in domestic PV systems.

- The largest energy losses were caused by sustained zero efficiency faults (when the PV system stopped generating for long periods) with a maximum annual loss for one system of $58.0 \%$. This demonstrates the need for alarm systems to alert system operators to these faults. A monitoring strategy for PV system clusters, capable of carrying out this task, has been discussed.

- Shading can occur for several months of the year but the overall energy losses are relatively low, due to low solar irradiation levels in winter months when the sun is at a low elevation. For one monitored PV system, seven months of shading resulted in a $6.9 \%$ reduction in annual energy generation. The calculation of shading energy losses would be essential in discussions with third parties if the removal of shading objects was necessary.

- Large numbers of brief low or zero efficiency faults, with durations of around 10 minutes or less, were observed for several of the monitored PV systems. These faults would remain undetected in monitoring schemes using hourly data but can cause significant energy losses (for example there was a maximum annual loss of $23 \%$ for one system in this study). Further work is needed to determine the cause of these faults and if similar faults are prevalent in other domestic PV systems.

This work has demonstrated the value of using high resolution measurements in studies of PV system performance. The data analysis techniques have been shown to be robust in explaining the faults that occur during PV system operation. The possibility of extending these techniques to monitoring studies of PV system clusters and of other urban micro-generation technologies has been discussed. This work is continuing and a follow-on study plans to utilise similar analysis techniques to investigate the supply and demand match between the electricity generation of the PV systems and the electricity consumption within the dwellings. 


\section{Acknowledgements}

This work was funded by the Integration of New and Renewable Energy into Buildings (INREB) Faraday Partnership. The specific assistance and funding of Energy for Sustainable Development Ltd is also gratefully acknowledged.

\section{References}

Baltus, C.W.A., van der Borg, N.J.C.M., van Dijk, V.A.P., Reinders, A.H.M.E., Kil, A.J., Zolingen, R.J.C., 1998. The suitability of several methods to quantify energy losses in PV systems. ECN report: ECN-C-98098, www.ecn.nl.

BRE, 2006. Domestic Photovoltaic Field Trials - Final Technical Report. Department of Trade and Industry contractor report, Building Research Establishment, Watford, UK, www.bre.co.uk/page.jsp?id=859

BSI, 1998. Photovoltaic system performance monitoring - guidelines for measurement, data exchange and analysis. British Standards Institution, BS EN 61724:1998.

Bücher, .K, 1997. Site dependence of the energy collection of PV modules, Solar Energy Materials and Solar Cells 47 (1997) 85-94

Bücher, K., Kunzelmann, S., 1998. The Fraunhofer ISE PV charts: Assessment of PV Device Performance. 2nd World Conference and Exhibition on Photovoltaic Solar Energy Conversion, Vienna, Austria, July 1998

Drews, A., de Keizer, A.C., Beyer, H.G., Lorenz, E., Betcke, J., van Sark, W.G.J.H.M., Heydenreich, W., Wiemken, E., Stettler, S., Toggweiler, P., Bofinger, S., Schneider, M., Heilscher, G., Heinemann, D., 2007. Monitoring and remote failure detection of grid-connected PV systems based on satellite observations. Solar Energy 81, $546-564$.

Erge, T., Hoffman, V.U., Kiefer, K., 2001. The German experience with grid-connected PV systems. Solar Energy 70, no. 6, pp. $479-487$.

Firth, S. Raising efficiency in photovoltaic systems: high resolution monitoring and performance analysis. PhD thesis, De Montfort University, Leicester, UK, 2006

IEA, 2000. Analysis of photovoltaic systems. International Energy Agency, report number: IEA-PVPS T201:2000, www.iea-pvps.org 
IEA, 2004. Country reports on PV system performance. International Energy Agency, IEA-PVPS report: T205:2004, www.iea-pvps.org

Kiefer, K., Körkel, T., Reinders, A., Rössler, E. and Wiemken, E., 1995. 2250 PV roofs in Germany operating results from intensified monitoring and analysis through numerical modelling. 13th EC PV Solar Energy Conference, Nice, France, 1995.

Oozeki, T., Izawa, T., Otani, K., Kurokawa, K., 2003. An evaluation method of PV systems. Solar Energy Materials and Solar Cells 75 (2003) $687-695$.

Pearsall, N.M., Hynes, K.M., 2003. Monitoring of domestic PV installations. Department of Trade and Industry contractor report: ETSU S/P2/00319/REP, www.dti.gov.uk

Reinders, A.H.M.E, van Dijk, V.A.P, Wiemken, E., Turkenburg, W.C., 1999. Technical and economic analysis of grid-connected PV systems by means of simulation. Progress in Photovoltaics, 7:71-82 (1999)

Roaf, S., Fuentes, M., 1999. Demonstration project for a 4 kW domestic photovoltaic roof in Oxford. Department of Trade and Industry contractor report ETSU S/P2/00236/REP/1, www.dti.gov.uk

RSI, 2005. Research Systems Inc, www.rsinc.com.

Uchida, D., Otani, K., Kurokawa, K., 2001. Evaluation of effective shading factor by fitting a clear-day pattern obtained from hourly maximum irradiance data. Solar Energy Materials and Solar Cells 67 (2001) 519-528. 


\section{Figures}

\section{List of figure captions}

Figure 1: An example of the PV systems installed at Site A (left) and Site B (right)

Figure 2: Monitored parameters for the PV systems

Figure 3: Five minutely in-plane solar irradiance to system efficiency values recorded over a one year period for a single monitored PV system

Figure 4: Distribution of system efficiency values in the $608 \mathrm{~W} / \mathrm{m} 2$ to $628 \mathrm{~W} / \mathrm{m} 2$ irradiance bin recorded over a one year period for a single monitored PV system

Figure 5: Normal operation and faults shown using five minutely in-plane solar irradiance to system efficiency values recorded over a one year period for a single monitored PV system

Figure 6: Sun position of faults for an example PV system at Site A during the first year of operation

Figure 7: Example of the sun position region used in fault concentration calculations for a fault with sun position $\alpha=11.5^{\circ}$ and $\beta=40.5$

Figure 8: Example of non-zero efficiency non-shading faults for an example PV system at Site B. The occurrence of the faults is plotted on date vs. time of day axes

Figure 9: Normal operation and fault categories shown using five minutely in-plane solar irradiance to system efficiency values recorded over a one year period for a single monitored PV system

Figure 10: Energy loss due to faults (as a percentage of normal operation final yield) for selected PV

Figure 11: Monthly normal operation final yield and shading energy loss for an example PV system with a deciduous tree to the south shading the array 
Table 1: Details of the PV installations

\begin{tabular}{|c|c|c|}
\hline & Site A & Site B \\
\hline Number of properties ${ }^{1}$ & 22 & 5 \\
\hline Location & East Midlands, UK & Yorkshire, UK \\
\hline Latitude & $52.9^{\circ} \mathrm{N}$ & $53.7^{\circ} \mathrm{N}$ \\
\hline Built form & Terraced bungalows & 2 storey blocks or flats \\
\hline Monitoring period & June 2002 to May 2004 & Dec 2003 to Nov 2004 \\
\hline $\begin{array}{l}\text { Size of PV systems } \\
(\mathrm{kWp})\end{array}$ & 1.53 to 1.7 & 1.44 and 1.68 \\
\hline Inverter rating $(\mathrm{W})$ & 2500 & 1100 \\
\hline Mounting system & Roof integrated & Roof mounted \\
\hline Array orientations ${ }^{2}$ & $-22^{\circ}$ & $-50^{\circ}$ and $30^{\circ}$ \\
\hline Array inclinations ${ }^{3}$ & $20^{\circ}$ & $37.5^{\circ}$ \\
\hline $\begin{array}{l}\text { Number of PV modules } \\
\text { per array }\end{array}$ & 18 to 20 & 8 to 12 \\
\hline Area of array $\left(\mathrm{m}^{2}\right)$ & 11.4 to 12.7 & 11.7 to 13.6 \\
\hline PV module type & Monocrystalline silicon & Polycrystalline silicon \\
\hline $\begin{array}{l}\text { PV module rated } \\
\text { efficiency }{ }^{4}\end{array}$ & $13.8 \%$ & $12.3 \%$ \\
\hline Sampling interval & $\approx 60$ seconds & $\approx 10$ seconds \\
\hline Recording interval & 5 minutes & 5 minutes \\
\hline
\end{tabular}

${ }^{1}$ Each property had an installed PV system

${ }^{2}$ The angle from due south where east is positive and west is negative

${ }^{3}$ The angle between the plane of the PV array and the horizontal

${ }^{4}$ The efficiency at Standard Test Conditions (STC) 
Table 2: Description of PV system faults and the four fault categories used in this study

\begin{tabular}{|c|c|c|c|}
\hline Fault & Description & Fault category & Diagnostic method \\
\hline $\begin{array}{l}\text { Component } \\
\text { failure } \\
\text { System isolation } \\
\text { - sustained }\end{array}$ & $\begin{array}{l}\text { Electricity generation ceases } \\
\text { completely due to component } \\
\text { failure or breakdown } \\
\text { Electricity generation ceases } \\
\text { completely due to the system } \\
\text { being isolated (i.e. switched } \\
\text { off for maintenance work) }\end{array}$ & $\begin{array}{l}\text { Sustained zero } \\
\text { efficiency fault }\end{array}$ & $\begin{array}{l}\text { Identify faults with } \\
\text { zero efficiency (no } \\
\text { power output) for long } \\
\text { time periods }\end{array}$ \\
\hline $\begin{array}{l}\text { Inverter } \\
\text { shutdown } \\
\text { System isolation } \\
\text { - brief }\end{array}$ & $\begin{array}{l}\text { Electricity generation ceases } \\
\text { completely due to a power cut } \\
\text { or variation in the grid } \\
\text { voltage } \\
\text { Electricity generation ceases } \\
\text { completely due to the system } \\
\text { being isolated (i.e. switched } \\
\text { off for maintenance work) }\end{array}$ & $\begin{array}{l}\text { Brief zero efficiency } \\
\text { fault }\end{array}$ & $\begin{array}{l}\text { Identify faults with } \\
\text { zero efficiency (no } \\
\text { power output) for short } \\
\text { time periods }\end{array}$ \\
\hline Shading & $\begin{array}{l}\text { Solar radiation blocked by } \\
\text { external shading objects, i.e. } \\
\text { buildings, trees }\end{array}$ & Shading fault & $\begin{array}{l}\text { Identify faults based on } \\
\text { the sun positions when } \\
\text { the faults occur }\end{array}$ \\
\hline $\begin{array}{l}\text { Inverter } \\
\text { maximum power } \\
\text { point (MPP) } \\
\text { tracking failure }\end{array}$ & $\begin{array}{l}\text { When MPP tracking causes a } \\
\text { significant reduction in } \\
\text { efficiency. Also known as } \\
\text { 'inverter dropout'. } \\
\text { Other faults that occur, which } \\
\text { are not identified as zero } \\
\text { efficiency or shading faults }\end{array}$ & $\begin{array}{l}\text { Non-zero efficiency } \\
\text { non-shading fault }\end{array}$ & $\begin{array}{l}\text { The faults remaining } \\
\text { after the zero efficiency } \\
\text { and shading faults have } \\
\text { been isolated. }\end{array}$ \\
\hline
\end{tabular}


Table 3: Mean and range of percentage of operational hours during which faults occurred

\begin{tabular}{|c|c|c|c|c|c|}
\hline \multirow[t]{2}{*}{ Site } & \multicolumn{5}{|c|}{ Percentage of operational hours during which faults occurred (\%) } \\
\hline & $\begin{array}{l}\text { Sustained } \\
\text { zero } \\
\text { efficiency } \\
\text { faults }\end{array}$ & $\begin{array}{l}\text { Brief zero } \\
\text { efficiency } \\
\text { faults }\end{array}$ & $\begin{array}{l}\text { Shading } \\
\text { faults }\end{array}$ & $\begin{array}{l}\text { Non-zero } \\
\text { efficiency } \\
\text { non-shading } \\
\text { faults }\end{array}$ & Total faults $^{3}$ \\
\hline \multirow{2}{*}{$\begin{array}{l}\text { Site A Year } 1 \\
(n=22)\end{array}$} & $1.1^{1}$ & 0.1 & 3.0 & 2.9 & 7.1 \\
\hline & 0 to $18.0^{2}$ & 0 to 1.1 & 0 to 8.1 & 1.7 to 4.5 & 1.8 to 27.9 \\
\hline \multirow{2}{*}{$\begin{array}{l}\text { Site A Year } 2 \\
(n=22)\end{array}$} & 3.4 & 0.3 & 3.1 & 1.3 & 8.2 \\
\hline & 0 to 41.6 & 0 to 2.2 & 0 to 9.6 & 0.5 to 1.8 & 0.5 to 47.5 \\
\hline \multirow{2}{*}{$\begin{array}{l}\text { Site B Year } 1 \\
(n=5)\end{array}$} & 11.7 & 1.3 & 0.6 & 6.2 & 19.9 \\
\hline & 0 to 58.6 & 0.1 to 4.9 & 0.1 to 1.5 & 1.6 to 12.9 & 6.0 to 60.7 \\
\hline
\end{tabular}

${ }^{1}$ Average values (\% of operational hours)

${ }^{2}$ Ranges: min to max (\% of operational hours)

3 The values for average total faults may not equal the sum of the individual fault values due to rounding 
Table 4: Annual electrical energy yields and losses due to faults

\begin{tabular}{|c|c|c|c|c|c|c|}
\hline \multirow[t]{2}{*}{ Site } & \multirow{2}{*}{$\begin{array}{l}\text { Actual } \\
\text { annual final } \\
\text { yield } \\
(\mathbf{k W h} / \mathbf{k W p})^{1}\end{array}$} & \multicolumn{4}{|c|}{ Loss in final yield due to faults (kWh/kWp) } & \multirow{2}{*}{$\begin{array}{l}\text { Normal } \\
\text { operation } \\
\text { annual final } \\
\text { yield } \\
(\mathbf{k W h} / \mathbf{k W p})\end{array}$} \\
\hline & & $\begin{array}{l}\text { Sustained } \\
\text { zero } \\
\text { efficiency } \\
\text { faults } \\
\end{array}$ & $\begin{array}{l}\text { Brief zero } \\
\text { efficiency } \\
\text { faults }\end{array}$ & $\begin{array}{l}\text { Shading } \\
\text { faults }\end{array}$ & $\begin{array}{l}\text { Non-zero } \\
\text { efficiency } \\
\text { non-shading } \\
\text { faults }\end{array}$ & \\
\hline \multirow{2}{*}{$\begin{array}{l}\text { Site A Year } 1 \\
(n=22)\end{array}$} & $775^{2}$ & 10 & 1 & 11 & 5 & 803 \\
\hline & 501 to $836^{3}$ & 0 to 166 & 0 to 11 & 0 to 38 & 3 to 7 & 703 to 849 \\
\hline \multirow{2}{*}{$\begin{array}{l}\text { Site A Year } 2 \\
(n=22)\end{array}$} & 745 & 33 & 3 & 12 & 3 & 796 \\
\hline & 315 to 834 & 0 to 395 & 0 to 19 & 0 to 54 & 1 to 4 & 736 to 843 \\
\hline \multirow{2}{*}{$\begin{array}{l}\text { Site B Year } 1 \\
(n=5)\end{array}$} & 469 & 66 & 13 & 2 & 28 & 577 \\
\hline & 232 to 563 & 0 to 328 & 1 to 49 & 0 to 5 & 4 to 84 & 555 to 599 \\
\hline
\end{tabular}

${ }^{1}$ By normalising with respect to the PV array rated power (the power output of the array under standard test conditions) this allows the electricity generation of arrays of different sizes to be compared

${ }^{2}$ Average values (kWh/kWp)

${ }^{3}$ Ranges: min to max (kWh/kWp) 
Table 5: Annual losses due to faults as a percentage of normal operation final yield

\begin{tabular}{|c|c|c|c|c|c|}
\hline \multirow[t]{2}{*}{ Site } & \multicolumn{5}{|c|}{ Loss in final yield due to faults (\%) } \\
\hline & $\begin{array}{l}\text { Sustained } \\
\text { zero } \\
\text { efficiency } \\
\text { faults }\end{array}$ & $\begin{array}{l}\text { Brief zero } \\
\text { efficiency } \\
\text { faults }\end{array}$ & $\begin{array}{l}\text { Shading } \\
\text { faults }\end{array}$ & $\begin{array}{l}\text { Non-zero } \\
\text { efficiency non- } \\
\text { shading faults }\end{array}$ & Total \\
\hline \multirow{2}{*}{$\begin{array}{l}\text { Site A Year } 1 \\
(n=22)\end{array}$} & $1.4^{1}$ & 0.2 & 1.4 & 0.6 & 3.6 \\
\hline & 0 to $23.6^{2}$ & 0 to 1.5 & 0 to 4.9 & 0.3 to 0.9 & 0.4 to 28.8 \\
\hline \multirow{2}{*}{$\begin{array}{l}\text { Site A Year } 2 \\
(n=22)\end{array}$} & 4.3 & 0.3 & 1.6 & 0.3 & 6.6 \\
\hline & 0 to 53.7 & 0 to 2.3 & 0 to 6.9 & 0.1 to 0.5 & 0.1 to 57.2 \\
\hline \multirow{2}{*}{$\begin{array}{l}\text { Site B Year } 1 \\
(n=5)\end{array}$} & 11.6 & 2.2 & 0.3 & 4.8 & 18.9 \\
\hline & 0 to 58 & 0.2 to 8.4 & 0.1 to 0.8 & 0.7 to 14.3 & 2.4 to 59 \\
\hline
\end{tabular}

${ }^{1}$ Average values (\%)

${ }^{2}$ Ranges: min to max (\%) 
Figure 1: An example of the PV systems installed at Site A (left) and Site B (right)
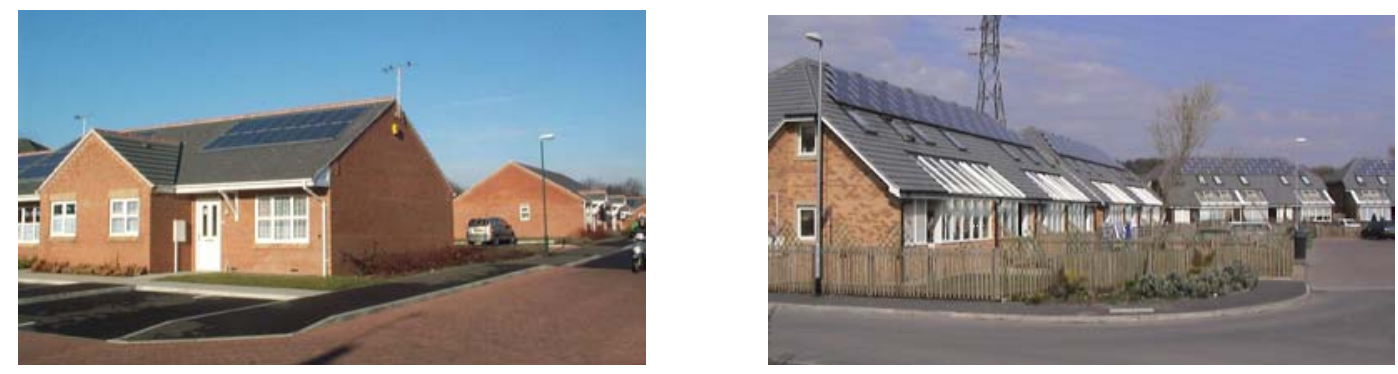
Figure 2: Monitored parameters for the PV systems

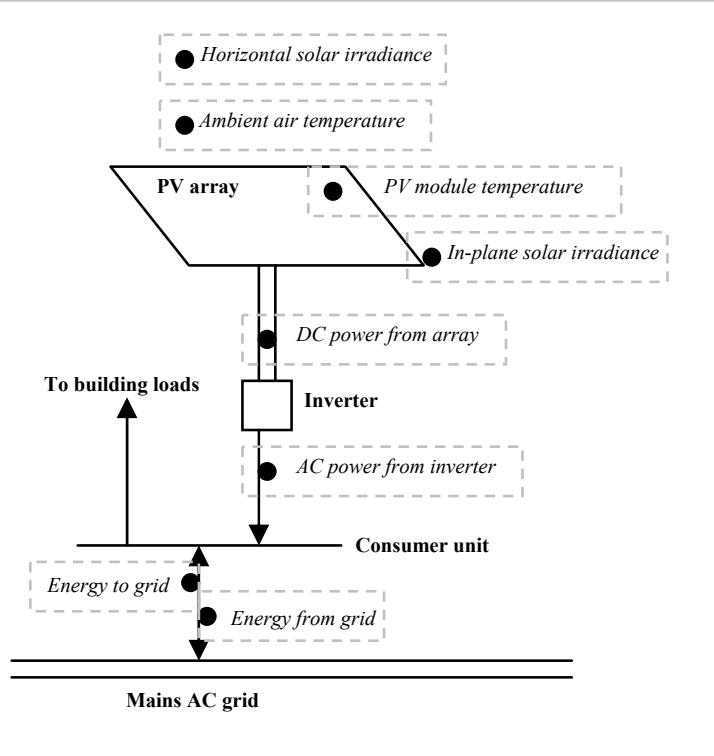


Figure 3: Five minutely in-plane solar irradiance to system efficiency values recorded over a one year period for a single monitored PV system

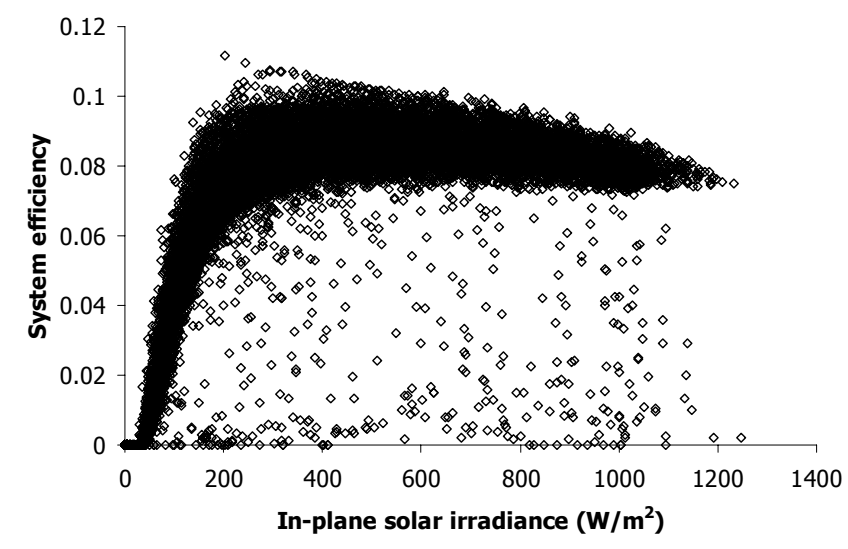


Figure 4: Distribution of system efficiency values in the $608 \mathrm{~W} / \mathrm{m}^{2}$ to $628 \mathrm{~W} / \mathrm{m}^{2}$ irradiance bin recorded over a one year period for a single monitored PV system

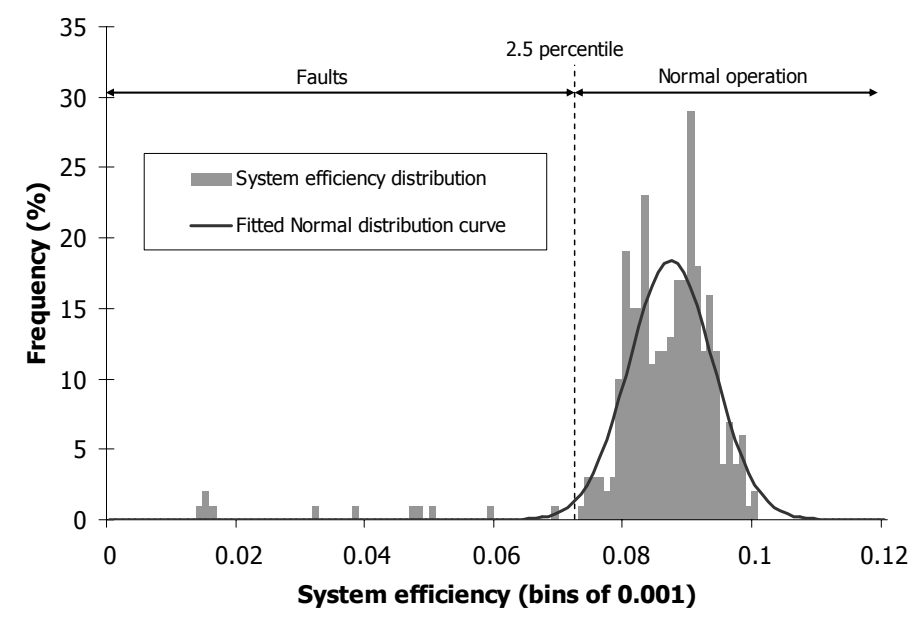




$$
5
$$


Figure 6: Sun position of faults for an example PV system at Site A during the first year of operation

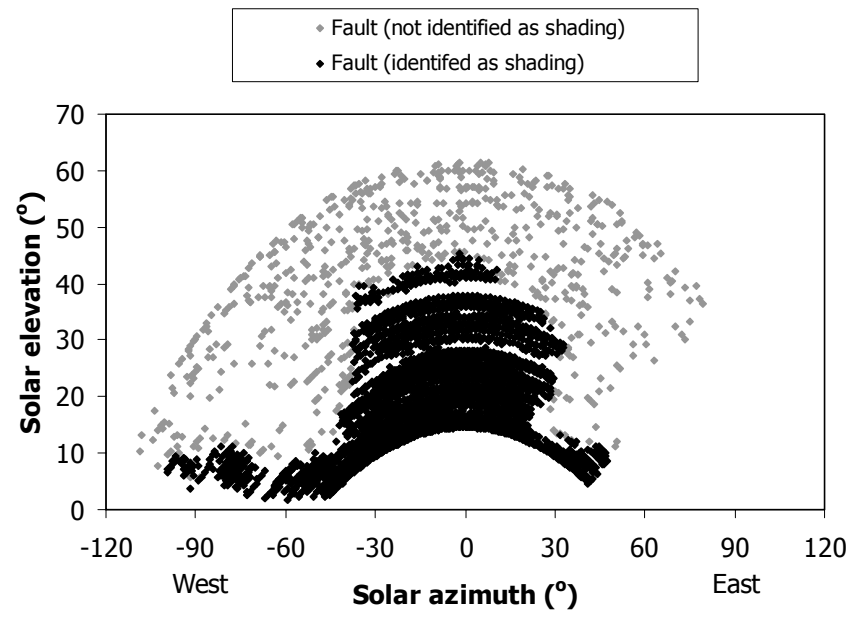


Figure 7: Example of the sun position region used in fault concentration calculations for a fault with sun position $\alpha=11.5^{\circ}$ and $\beta=40.5$

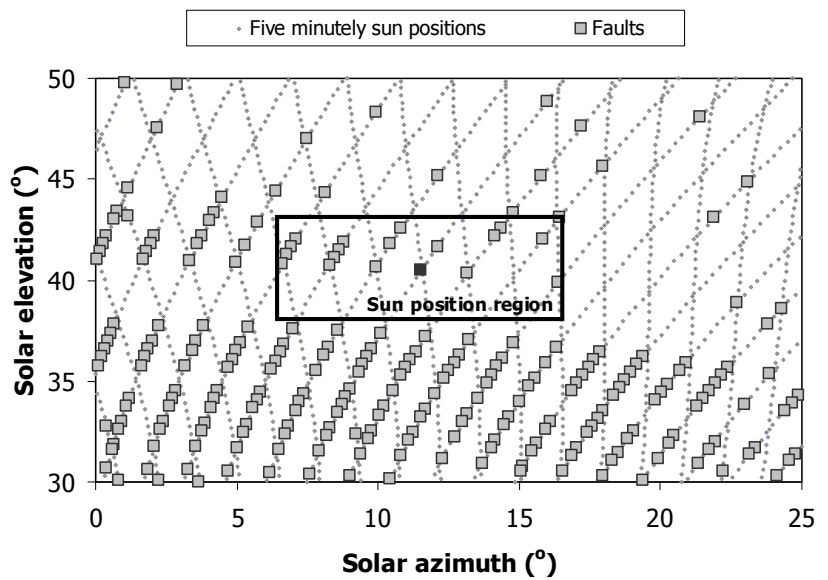


Figure 8: Example of non-zero efficiency non-shading faults for an example PV system at Site B. The occurrence of the faults is plotted on date vs. time of day axes

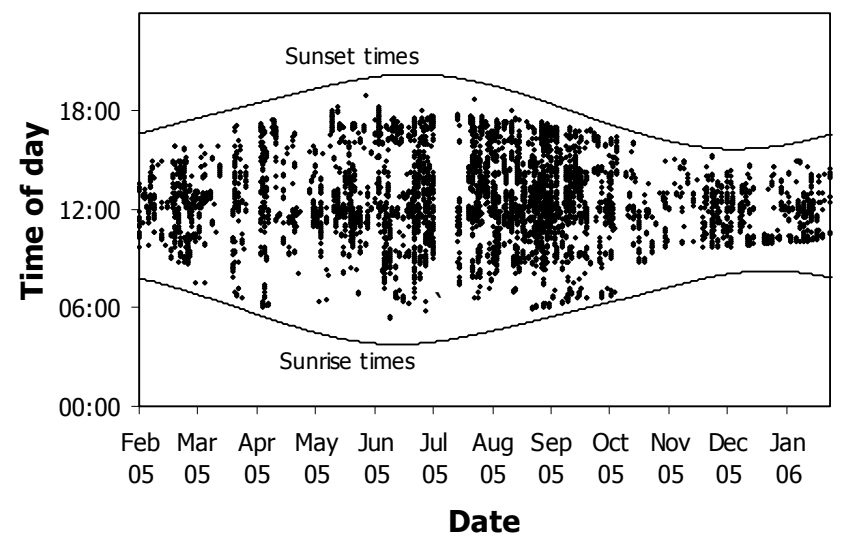


Figure 9: Normal operation and fault categories shown using five minutely in-plane solar irradiance to system efficiency values recorded over a one year period for a single monitored PV system

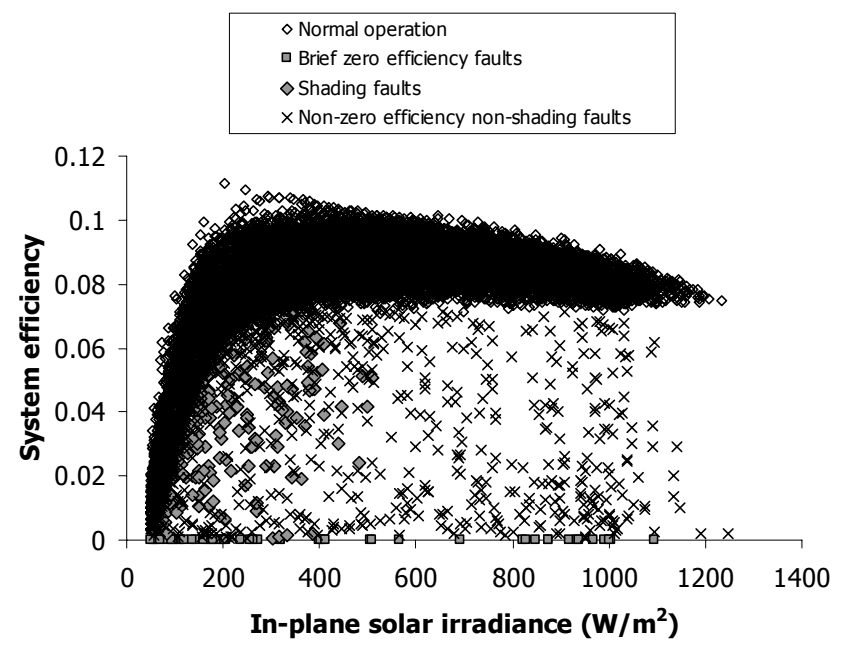


Figure 10: Energy loss due to faults (as a percentage of normal operation final yield) for selected PV systems with a total energy loss greater than $5 \%$ in the first year of operation

- Sustained zero efficiency faults

$\square$ Brief zero efficiency faults

$\square$ Shading

요 Non-zero efficiency non-shading faults

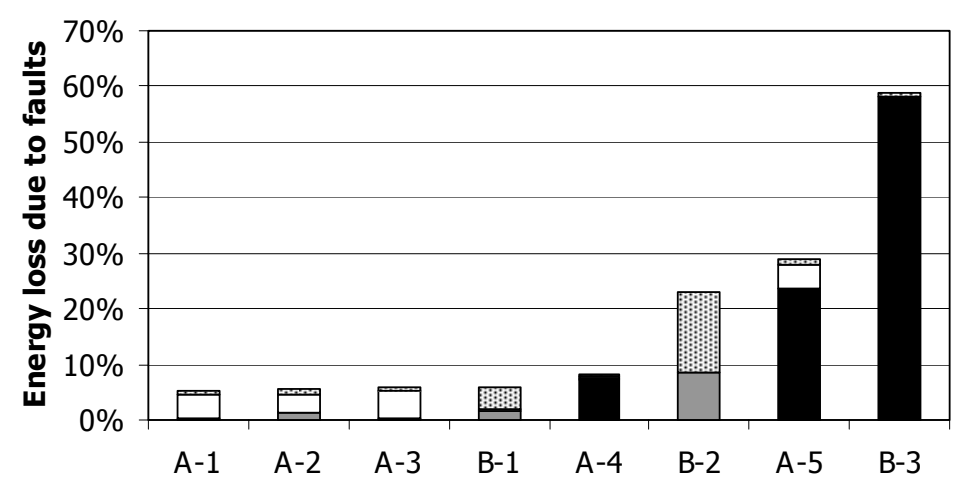

Site - System number 
Figure 11: Monthly normal operation final yield and shading energy loss for an example PV system with a deciduous tree to the south shading the array

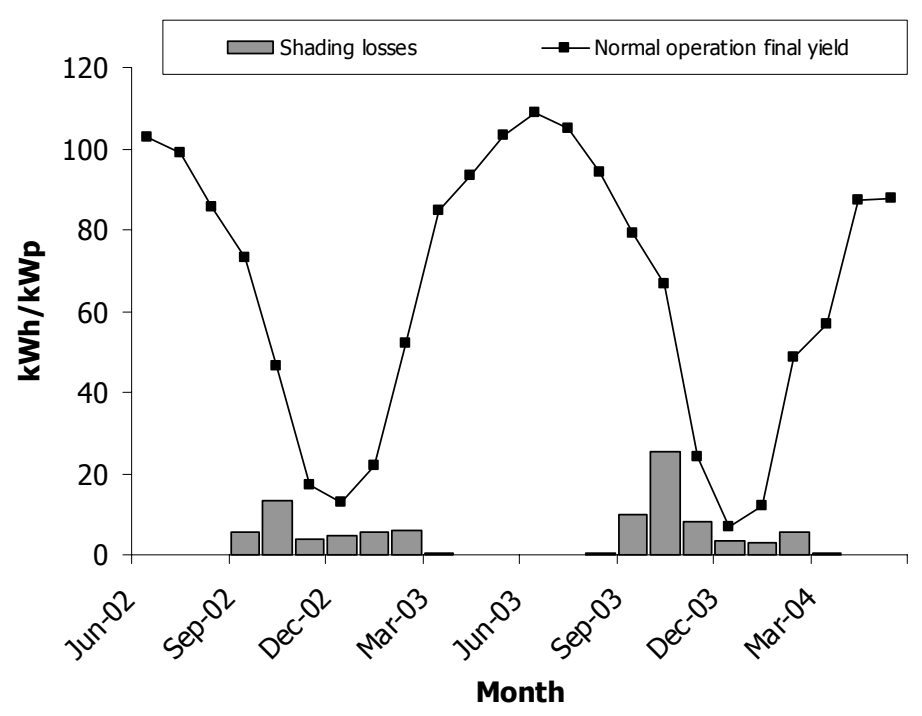

